\title{
BMJ
}

\section{Effect of supplementation during pregnancy with L-arginine and antioxidant vitamins in medical food on pre-eclampsia in high risk population: randomised controlled trial}

\author{
Felipe Vadillo-Ortega, professor, ${ }^{1}$ Otilia Perichart-Perera, titular researcher, ${ }^{2}$ Salvador Espino, associate \\ professor of obstetrics and gynaecology, ${ }^{2}$ Marco Antonio Avila-Vergara, associate professor of obstetrics and \\ gynaecology, ${ }^{3}$ Isabel Ibarra, associate professor, ${ }^{4}$ Roberto Ahued, professor of obstetrics and gynaecology, ${ }^{2}$ \\ Myrna Godines, associate professor of obstetrics and gynaecology, ${ }^{1}$ Samuel Parry, associate professor and \\ chief of division of maternal-fetal medicine, ${ }^{5}$ George Macones, Mitchell and Elaine Yanow professor and head \\ of obstetrics and gynaceology, 5,6 Jerome F Strauss, professor of obstetrics and gynaecology and dean of \\ School of Medicine
}

${ }^{1}$ Department of Experimental Medicine, School of Medicine, Universidad Nacional, Autonoma de Mexico, Torre de Investigacion, 3er Piso, Ciudad Universitaria, Mexico, D F 04510

${ }^{2}$ Instituto Nacional de

Perinatologia Isidro Espinosa de los, Reyes, Mexico

${ }^{3}$ Universidad Autonoma de Sinaloa, Mexico

${ }^{4}$ Instituto de Investigaciones Biomedicas, UNAM, Mexico

${ }^{5}$ Department of Obstetrics and Gynaecology, University of Pennsylvania, Philadelphia, PA, USA

${ }^{6}$ Department of Obstetrics and Gynaecology, Washington University, St Louis, MO, USA ${ }^{7}$ Department of Obstetrics and Gynaecology, Virginia Commonwealth University, Richmond, VA, USA

Correspondence to: F VadilloOrtega felipe.vadillo@gmail.com

Cite this as: $B M J$ 2011;342:d2901 doi:10.1136/bmj.d2901

\section{ABSTRACT}

Objective To test the hypothesis that a relative deficiency in L-arginine, the substrate for synthesis of the vasodilatory gas nitric oxide, may be associated with the development of pre-eclampsia in a population at high risk.

Design Randomised, blinded, placebo controlled clinical trial.

Setting Tertiary public hospital in Mexico City.

Participants Pregnant women with a history of a previous pregnancy complicated by pre-eclampsia, or preeclampsia in a first degree relative, and deemed to be at increased risk of recurrence of the disease were studied from week 14-32 of gestation and followed until delivery. Interventions Supplementation with a medical foodbars containing L-arginine plus antioxidant vitamins, antioxidant vitamins alone, or placebo-during pregnancy.

Main outcome measure Development of pre-eclampsia/ eclampsia.

Results 222 women were allocated to the placebo group, 228 received $L$-arginine plus antioxidant vitamins, and

222 received antioxidant vitamins alone. Women had 4-8 prenatal visits while receiving the bars. The incidence of pre-eclampsia was reduced significantly $\left(X^{2}=19.41\right.$; $\mathrm{P}<0.001)$ in women randomised to $\mathrm{L}$-arginine plus antioxidant vitamins compared with placebo (absolute risk reduction 0.17 (95\% confidence interval 0.12 to 0.21). Antioxidant vitamins alone showed an observed benefit, but this effect was not statistically significant compared with placebo $\left(X^{2}=3.76 ; P=0.052\right.$; absolute risk reduction $0.07,0.005$ to 0.15$)$. L-arginine plus antioxidant vitamins compared with antioxidant vitamins alone resulted in a significant effect $(P=0.004$; absolute risk reduction $0.09,0.05$ to 0.14 ).

Conclusions Supplementation during pregnancy with a medical food containing L-arginine and antioxidant vitamins reduced the incidence of pre-eclampsia in a population at high risk of the condition. Antioxidant vitamins alone did not have a protective effect for prevention of pre-eclampsia. Supplementation with Larginine plus antioxidant vitamins needs to be evaluated in a low risk population to determine the generalisability of the protective effect, and the relative contributions of Larginine and antioxidant vitamins to the observed effects of the combined treatment need to be determined. Trial registration Clinical trials NCT00469846.

\section{INTRODUCTION}

Pre-eclampsia and eclampsia are among the leading causes of maternal and neonatal morbidity and mortality. ${ }^{1}$ Despite growing knowledge of the pathophysiology of pregnancy induced hypertensive disorders, no preventive measures have been shown to be effective. $^{2}$ The underlying cause of pre-eclampsia/ eclampsia is thought to be abnormal placentation, characterised by defective invasion of trophoblast cells and remodelling of the uterine vasculature, ${ }^{3}$ resulting in reduced utero-placental perfusion, which leads to activation of mechanisms promoting maternal vasoconstriction and activation or damage of endothelial cells. ${ }^{4}$ The endothelium is believed to be a primary target of mediators generated by the placenta. Damage is amplified by other factors such as reactive oxygen species. ${ }^{5}$

Nitric oxide is a potent endothelium derived vasodilator, ${ }^{6}$ and defective synthesis of nitric oxide has been documented in pre-eclampsia. ${ }^{7}$ The main site of production of nitric oxide is nitric oxide synthase in endothelial cells, which uses circulating L-arginine as a substrate. Hence, the local availability of this amino acid may be critical to the endothelial adaptive regulatory mechanisms opposing the vasoconstrictors in pre-eclampsia. L-arginine is considered to be a semiessential amino acid because under increased demands endogenous synthesis is not sufficient to fulfil 
requirements. $^{8}$ Moreover, pregnancy has been reported to be a state of relative arginine deficiency, ${ }^{7}$ imposed by the increased formation of nitric oxide, supporting the adaptive vasodilatation of pregnancy, and use of L-arginine by the fetus. ${ }^{9}$ Pre-eclampsia is also associated with increased concentrations of factors that inhibit nitric oxide production. Concentrations of asymmetric dimethyl arginine, a competitive inhibitor of nitric oxide synthase, are raised in women with preeclampsia. ${ }^{10}$ Concentrations of soluble fms-like tyrosine kinase 1, which antagonises vascular endothelial growth factor dependent activation of nitric oxide synthase, have also been shown to be increased in preeclampsia. ${ }^{11}$ Endoglin, which impairs activation of nitric oxide synthase mediated by transforming growth factor $\beta$, is also increased. ${ }^{12}$

In the past, the role of nutrition in the development of pre-eclampsia has been a subject of considerable discussion. Although little evidence exists to show that dietary manipulations can prevent pre-eclampsia, the notion that they might moderate the secondary features of the syndrome remains in favour. ${ }^{13}$ Substantial experimental data in animals and humans indicate that L-arginine could have a beneficial effect on haemodynamics. ${ }^{14-16}$ Of particular note, an expanding literature documents that administration of L-arginine improves vascular function in people with atherosclerosis and peripheral vascular disease. ${ }^{17-20}$ The oral administration of L-arginine to patients with cardiovascular disease has not been associated with any significant adverse side effects. This includes previous reports in the literature of use of L-arginine in pregnant women. Facchinetti et al and Neri et al infused L-arginine into women whose pregnancies were complicated by intrauterine growth retardation and reported reduced myometrial activity. ${ }^{2122}$ These observations raised the possibility that supplemental L-arginine in the diet could provide a source of substrate for nitric oxide synthesis during pregnancy, which could promote vasodilatation. More clinical studies are needed in this area because we have limited experience in the use of L-arginine and other nitric oxide donators for preventing pre-eclampsia, as stated in the Cochrane review by Meher and Duley. ${ }^{23}$ On the other hand, evidence of endothelial damage mediated by reactive oxygen species has been proposed as another mechanism of endothelial damage in preeclampsia. ${ }^{24-26}$ Consequently, antioxidants have been proposed as prophylactic agents for pre-eclampsia and several trials with antioxidants including vitamin $\mathrm{C}$ and tocopherols in pre-eclampsia have been published. ${ }^{27-29}$ At the time this clinical trial was started, insufficient evidence existed for us to discard the use of antioxidants for prevention of pre-eclampsia. However, recent trials and Cochrane reviews do not support the use of antioxidants for this purpose. ${ }^{3031} \mathrm{We}$ did a three arm clinical trial to test the hypothesis that a combination of $\mathrm{L}$ arginine and antioxidant supplementation would reduce the risk of pre-eclampsia in a high risk population in Mexico City.

\section{METHODS}

Study participants

We enrolled pregnant women between 14 and 32 weeks of gestation at high risk of pre-eclampsia who were receiving prenatal care at the Instituto Nacional de Perinatologia Isidro Espinosa de los Reyes in Mexico City between January 2001 and December 2005. We included patients at increased risk of pre-eclampsia, which we defined as either a personal history of pre-eclampsia or pre-eclampsia in a first degree relative. Eligible participants agreed to have their prenatal care and delivery at the institution and provide informed consent. We excluded patients with multiple gestation, known major fetal anomalies (as defined by ultrasound studies by the fetal medicine department), diabetes mellitus or gestational diabetes, pre-existing hypertension, pre-existing renal disease, collagen vascular disease, cancer or strong family history of cancer in first degree relatives, and pre-existing maternal disease needing drug treatment. We excluded women with type 2 diabetes, cancer, or a strong family history of cancer because the angiogenic actions of vascular endothelial growth factor are thought to be mediated, in part, by nitric oxide. ${ }^{32}$ All women were screened for gestational diabetes at week 14 and again at week 24 of gestation, according to the institutional protocol. We decided in advance that if a woman was diagnosed as having gestational diabetes after randomisation she would discontinue taking bars because of the aforementioned safety concerns. However, we included such women in the data analysis. We excluded patients with autoimmune disease because peroxynitrites have been implicated in the pathogenesis of tissue damage in autoimmune disease.

\section{Recruitment and randomisation}

Staff of the department of obstetrics reviewed prenatal records to identify patients who might qualify for the study. A history of pre-eclampsia was confirmed by review of the patient's records, and a family history of pre-eclampsia was based on patients' self report. Gestational age was assessed by last menstrual period and confirmed by a first trimester ultrasound evaluation. The protocol for recruitment included an initial visit in which suitability for randomisation was evaluated, an invitation to participate was tendered, a complete obstetric and nutritional history was taken, and written informed consent was obtained. Participants were randomly assigned to receive one of the three treatments. The principal investigator made the assignment centrally after the patient had given informed consent, by using a computer generated code in random size blocks with concealment of allocation by sealed envelopes.

Each participant in the L-arginine plus antioxidant vitamins group received two bars a day. The average consumption of L-arginine in the United States is around $5.4 \mathrm{~g}$ a day, ${ }^{8}$ so we decided to supplement at least $100 \%$ of this amount in the form of an available medical food (Heart Bars, Nellson Nutraceutical, CA, USA). Two Heart Bars a day deliver $6.6 \mathrm{~g}$ of L-arginine 
and antioxidant vitamins. ${ }^{33}$ Table 1 shows the composition of the bars used in the study. Participants in the antioxidant vitamins alone group received two bars a day devoid of L-arginine but containing antioxidant vitamins. Participants in the placebo group received two placebo bars a day devoid of L-arginine and antioxidant vitamins.

The bars were packaged in similar envelopes that made them indistinguishable by appearance, and they were flavoured such that they had the same taste irrespective of composition. The bars were packed in boxes containing a sufficient supply for five weeks of treatment. Only the principal investigator knew the group codes. We asked participants to consume bars until the day of delivery. A basal sample of blood was taken at the randomisation visit, and protein was measured in a 24 hour urine sample before participants started the consumption of bars.

\section{Clinical follow-up}

Participants were scheduled for clinical follow-up every three to four weeks. Each visit from this point included the following: (1) Arterial pressure measurement. Measurements of the arterial pressure were made according to the recommendations of the American Heart Association (AHA) using the auscultatory method with mercury sphygmomanometers. ${ }^{34}$ All staff collecting arterial pressure measurements were certified by external monitors from the AHA, who made site visits to the hospital. (2) A sample of $10 \mathrm{~mL}$ of venous blood was collected for determination of $\mathrm{L}$ arginine concentration. Plasma was separated and maintained at $-80^{\circ} \mathrm{C}$ until analysis. (3) Participants were instructed to obtain a 24 hour urine sample the

\begin{tabular}{|c|c|}
\hline Compound & Content \\
\hline Total fat & $2.0 \mathrm{~g}$ \\
\hline Saturated fat & $0.5 \mathrm{~g}$ \\
\hline Polyunsaturated fat & $1.0 \mathrm{~g}$ \\
\hline Monounsaturated fat & $0.5 \mathrm{~g}$ \\
\hline Trans fat & $0 \mathrm{~g}$ \\
\hline Cholesterol & $10 \mathrm{mg}$ \\
\hline Sodium & $65 \mathrm{mg}$ \\
\hline Potassium & $100 \mathrm{mg}$ \\
\hline Total carbohydrate & $19 \mathrm{~g}$ \\
\hline Dietary fibre & $1.0 \mathrm{~g}$ \\
\hline Sugars & $12.0 \mathrm{~g}$ \\
\hline Protein & $9.0 \mathrm{~g}$ \\
\hline L-arginine & $3.3 \mathrm{~g}$ \\
\hline Vitamin C & $250 \mathrm{mg}$ \\
\hline Vitamin E & $200 \mathrm{UI}$ \\
\hline Niacin & $25 \mathrm{mg}$ \\
\hline Vitamin B-6 & $2.0 \mathrm{mg}$ \\
\hline Vitamin B-12 & $4.8 \mu \mathrm{g}$ \\
\hline Folate & $200 \mu \mathrm{g}$ \\
\hline
\end{tabular}

Each bar weighed $35 \mathrm{~g}$ and contained $534 \mathrm{~kJ}(130 \mathrm{kcal})$; bars for placebo group were devoid of L-arginine and antioxidant vitamins; bars for antioxidant vitamins group were devoid of L-arginine. day before the next visit. We assessed urine protein by quantification in 24 hour urine samples with an automated method (DiaSys Diagnostic Systems, Holsheim, Germany). ${ }^{35}$ (4) To measure compliance, we gave each patient a personal diary to record consumption of bars, which they brought to every appointment. We also instructed them to keep the empty envelopes of the consumed bars, which they also brought back at each appointment. (5) We offered nutritional education and assessment of nutritional status during pregnancy to all participants. We instructed them to avoid the consumption of over the counter prenatal antioxidant vitamins and asked about non-study related vitamin ingestion at each visit.

\section{End points}

We defined pre-eclampsia as hypertension (systolic blood pressure $\geq 140 \mathrm{~mm} \mathrm{Hg}$, diastolic blood pressure $\geq 90 \mathrm{~mm} \mathrm{Hg}$, or both) and proteinuria (>300 mg/24 hours) presenting after 20 weeks of gestation in women known to be previously normotensive. We defined eclampsia as non-epileptic convulsions. We defined mild pre-eclampsia as when hypertension and proteinuria were present but no evidence of systemic organ damage was detectable. Severe preeclampsia was detected when proteinuria was above $2.0 \mathrm{~g} / 24$ hours, blood pressure was $\geq 160 / 110 \mathrm{~mm}$ $\mathrm{Hg}$, or both. We also assessed several neonatal end points, including preterm birth (born before 37 weeks of gestation), birth weight, small for gestational age (according to institutional charts), and Apgar scores.

We based the sample size calculation on consideration of all three two way comparisons (placebo $v$ antioxidant vitamins alone, placebo $v$ antioxidant vitamins plus L-arginine, and antioxidant vitamins plus L-arginine $v$ antioxidant vitamins alone), assuming a 50\% proportional reduction in pre-eclampsia in any group compared with placebo, an $\alpha$ error of 0.05 , a $\beta$ error of 0.2 , and a 1:1:1 allocation ratio. We used a Bonferroni correction so that a test specific error $(\alpha)$ of $0.016(0.05 / 3)$ was used for significance testing of all primary two way comparisons. We also used the $\alpha$ error of 0.016 in our sample size estimation. We assumed a prevalence of preeclampsia in the placebo group of 30\% (on the basis of pilot data from our institution).

\section{L-arginine assays}

We measured L-arginine concentrations by high performance liquid chromatography after derivatisation with the o-phthalaldehyde-ethanethiol reagent as described by Lundsjo et al. ${ }^{36}$ The derivatised samples were separated by using a reversed phase Kingsorb $3 \mu$ C18 column (Phenomenex, Torrace, CA) according to the standard method. We used peak areas for quantification of L-arginine concentrations, using an external standard as reference. We report values as $\mu \mathrm{M}$ in plasma. We monitored within assay and between assay coefficients of variation and maintained them under $3 \%$. 
Table 2 | Baseline characteristics of participants. Values are means (SD) unless stated otherwise

\begin{tabular}{lcccc} 
Characteristic & $\begin{array}{c}\text { Placebo } \\
(\mathrm{n}=222)\end{array}$ & $\begin{array}{c}\text { L-arginine } \\
+ \text { vitamins } \\
(\mathrm{n}=228)\end{array}$ & $\begin{array}{c}\text { Vitamins } \\
\text { alone } \\
(\mathrm{n}=222)\end{array}$ & P value \\
Age (years) & $28.2(5.1)$ & $28.0(6.1)$ & $27.6(5.5)$ & $0.47^{*}$ \\
\hline Gestational age at enrolment (weeks) & $21.1(4.7)$ & $20.9(4.6)$ & $21.1(5.3)$ & $0.84^{\star}$ \\
\hline $\begin{array}{l}\text { Previous gestation with pre-eclampsia/first } \\
\text { degree relative with pre-eclampsia }\end{array}$ & $211 / 11$ & $218 / 10$ & $209 / 13$ & $0.65 \dagger$ \\
\hline Median (range) parity & $2(1-9)$ & $2(1-6)$ & $2(1-6)$ & $0.09 \dagger$ \\
\hline Median (range) vaginal deliveries & $0(0-5)$ & $0(0-3)$ & $0(0-6)$ & $0.42 \dagger$ \\
\hline Median (range) previous caesarean sections & $1(0-2)$ & $1(0-3)$ & $1(0-3)$ & $0.48 \dagger$ \\
\hline Median (range) abortions & $0(0-5)$ & $0(0-3)$ & $0(0-2)$ & $0.13 \dagger$ \\
\hline Systolic blood pressure at enrolment $(\mathrm{mm} \mathrm{Hg})$ & $105.1(9.8)$ & $105.4(8.8)$ & $105.6(8.8)$ & $0.86^{*}$ \\
\hline Diastolic blood pressure at enrolment $(\mathrm{mm} \mathrm{Hg})$ & $68.3(9.1)$ & $67.2(8.7)$ & $67.6(7.9)$ & $0.40^{\star}$ \\
\hline Plasma L-arginine $(\mu M)$ & $21.9(8.5)$ & $22.7(8.3)$ & $21.9(9.2)$ & $0.52^{\star}$ \\
\hline Pre-gestational body mass index & $26.8(4.9)$ & $27.5(5.3)$ & $26.1(4.1)$ & $0.28^{*}$ \\
\hline Smoked during pregnancy & 5 & 4 & 6 & $0.87 \dagger$ \\
\hline
\end{tabular}

*Analysis of variance.

†Kruskal-Wallis test. women had a direct relative who had developed preeclampsia, and they were equally distributed among the three arms in this study. Six hundred and twentyeight women had a previous pregnancy complicated by pre-eclampsia. We allocated 222 women to the placebo group, 228 women received the L-arginine plus antioxidant vitamins bars, and 222 women received the bars with antioxidant vitamins alone. The treatment groups were well balanced with regards to baseline characteristics (table 2).

Clinical follow-up was similar among the women included in the analysis. All groups had a median of 5 (range 2-9) visits during the study (Kruskal-Wallis, $\mathrm{P}=0.21$ ). Less than $5 \%$ of study visits were missed for all three groups. In terms of compliance, the placebo group consumed a mean of 1.1 (SD 0.5) bars a day, the L-arginine plus antioxidant vitamins group consumed $1.2(0.4)$ bars a day, and the vitamins alone group consumed 1.1 (0.43) bars a day (analysis of variance, $\mathrm{P}=0.23)$. The nutritionists developed several strategies to promote compliance. Briefly, patients were instructed to mix bars with other foods such as yoghurt, gelatine, milk shakes, or fruit.

Reported side effects were significantly more frequent in the group consuming L-arginine plus antioxidant vitamins bars than in the placebo group, including nausea $(\mathrm{P}=0.019$; absolute risk reduction $0.05,95 \%$ confidence interval 0.02 to 0.08 ; relative risk $1.25,1.04$ to 1.51 ); symptoms of dyspepsia $(\mathrm{P}=0.04 ; 0.03,0.01$ to $0.06 ; 1.34,1.02$ to 1.77$)$; dizziness $(\mathrm{P}=0.039 ; 0.03,0.01$ to $0.05 ; 1.42,1.02$ to 1.97$)$; palpitations $(\mathrm{P}=0.019 ; 0.04,0.01$ to $0.07 ; 1.36,1.05$ to $1.76)$; and headache $(\mathrm{P}=0.01 ; 0.06,0.03$ to $0.09 ; 1.26$, 1.06 to 1.51). None of these side effects led to a participant dropping out of the study.

One hundred and twenty-five patients discontinued their assigned treatment. However, we followed them up until the end of pregnancy and included them analytically in the group to which they were randomised. Fifty-six women decided to drop out of the study voluntarily: 18 in the placebo group, 17 in the L-arginine plus antioxidant vitamins group, and 21 in the

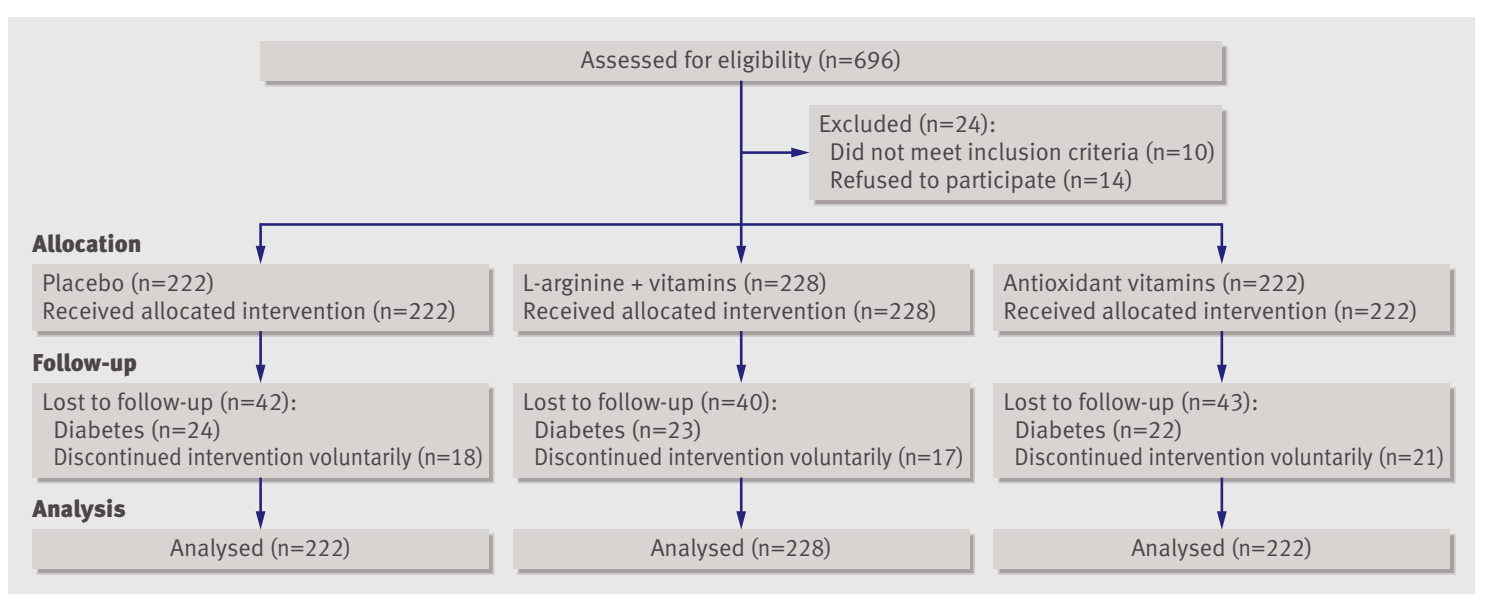


Table 3 |Clinical outcomes

\begin{tabular}{|c|c|c|c|c|c|c|}
\hline & \multicolumn{3}{|c|}{ No $(\%)^{\star}$} & \multicolumn{3}{|c|}{ Absolute risk reduction $(95 \% \mathrm{Cl})$; relative risk $(95 \% \mathrm{Cl})^{*}$} \\
\hline & $\begin{array}{l}\text { Placebo } \\
(n=222)\end{array}$ & $\begin{array}{l}\text { L-arginine } \\
+ \text { vitamins } \\
\quad(n=228)\end{array}$ & $\begin{array}{l}\text { Vitamins } \\
\text { alone } \\
(n=222)\end{array}$ & $\begin{array}{l}\text { L-arginine }+ \text { vitamins } \\
\qquad v \text { placebo }\end{array}$ & $\begin{array}{l}\text { Vitamins alone } \\
v \text { placebo }\end{array}$ & $\begin{array}{l}\text { L-arginine }+ \text { vitamins } \\
v \text { vitamins alone }\end{array}$ \\
\hline \multicolumn{7}{|l|}{ Primary outcome } \\
\hline Pre-eclampsia or eclampsia & $67(30)$ & 29 (13) & $50(23)$ & $\begin{array}{l}0.17(0.12 \text { to } 0.21) ; 0.42 \\
(0.28 \text { to } 0.62)\left(X^{2}: P<0.001\right)\end{array}$ & $\begin{array}{c}0.07(0.005 \text { to } 0.15) ; 0.74(0.54 \\
\text { to } 1.02)\left(X^{2}: P=0.052\right)\end{array}$ & $\begin{array}{c}0.09(0.05 \text { to } 0.14) ; 0.56 \\
(0.37 \text { to } 0.85)\left(x^{2}: P=0.004\right)\end{array}$ \\
\hline \multicolumn{7}{|l|}{ Secondary outcomes } \\
\hline Total preterm delivery & $44(20)$ & $24(11)$ & $52(23)$ & $\begin{array}{l}0.09(0.05 \text { to } 0.13) ; 0.53 \\
(0.33 \text { to } 0.84)\left(x^{2}: P=0.003\right)\end{array}$ & $\begin{array}{c}0.03(-0.02 \text { to } 0.09) ; 1.18(0.82 \\
\text { to } 1.68)\left(X^{2}: P=0.419\right)\end{array}$ & $\begin{array}{l}0.12(-0.08 \text { to } 0.17) ; 0.44 \\
(0.28 \text { to } 0.70)\left(x^{2}: P<0.001\right)\end{array}$ \\
\hline Spontaneous preterm delivery & $13(6)$ & $12(5)$ & $15(7)$ & $\begin{array}{l}0.005(-0.03 \text { to } 0.02) ; 0.89 \\
(0.41 \text { to } 1.92)\left(x^{2}: P=0.631\right)\end{array}$ & $\begin{array}{l}0.009(-0.02 \text { to } 0.04) ; 1.15 \\
(0.56 \text { to } 2.36)\left(X^{2}: P=0.845\right)\end{array}$ & $\begin{array}{l}0.01(-0.04 \text { to } 0.14) ; 0.77 \\
(0.37 \text { to } 1.62)\left(X^{2}: P=0.386\right)\end{array}$ \\
\hline Caesarean section & $152(68.4)$ & $155(67.9)$ & $148(66.6)$ & $\begin{array}{c}-0.004(-0.67 \text { to } 0.57) ; 0.99 \\
(0.87 \text { to } 1.12)\left(x^{2}: P=0.832\right)\end{array}$ & $\begin{array}{l}-0.01(-0.08 \text { to } 0.04) ; 0.97 \\
(0.85 \text { to } 1.10)\left(x^{2}: P=0.612\right)\end{array}$ & $\begin{array}{l}0.01(-0.04 \text { to } 0.75) ; 1.01 \\
(0.89 \text { to } 1.15)\left(x^{2}: P=0.843\right)\end{array}$ \\
\hline $\begin{array}{l}\text { Mean (SD) gestational age at } \\
\text { delivery }\end{array}$ & $38.4(2.2)$ & $39.0(1.9)$ & $38.6(1.9)$ & $0.65(0.27$ to 1.04$) \dagger(\mathrm{P}=0.001)$ & $0.29(-0.68$ to 0.09$) \dagger(P=0.13)$ & $0.35(-0.7$ to 0.004$)+(P=0.051)$ \\
\hline Sex of baby (F/M) & $115 / 107$ & $117 / 111$ & $110 / 112$ & $X^{2}: P=0.993$ & $X^{2}: P=0.704$ & $X^{2}: P=0.780$ \\
\hline \multicolumn{7}{|l|}{ Mean (SD) Apgar score: } \\
\hline 1 minute & $7.8(1.1)$ & $8.2(0.8)$ & $8.0(0.8)$ & $0.44(0.24$ to 0.64$) \dagger(P=0.000)$ & $0.25(0.04$ to 0.47$) \dagger(P=0.015)$ & $0.18(0.01$ to 0.36$) \dagger(P=0.04)$ \\
\hline 5 minutes & $8.7(0.7)$ & $8.9(0.3)$ & $8.9(0.3)$ & $0.21(0.10$ to 0.33$) \dagger(P=0.000)$ & $0.16(0.05$ to 0.46$) \dagger(P=0.007)$ & $0.05(0.02$ to 0.12$) \dagger(P=0.18)$ \\
\hline Mean (SD) neonatal weight (g) & $3070.2(470)$ & $2988.6(506)$ & $2990.7(451)$ & $81,(-15$ to 179$)+(P=0.1)$ & $2(-102$ to 98$) \dagger(P=0.96)$ & $79(-17$ to 175$) \dagger(P=0.1)$ \\
\hline Mean (SD) neonatal length $(\mathrm{cm})$ & $48.5(3.0)$ & $47.9(3.5)$ & $47.8(2.9)$ & $0.6(-1.2$ to 0.1$) \dagger(P=0.10)$ & $0.1(-0.6$ to 0.8$) \dagger(P=0.78)$ & $0.7(0.03$ to 1.3$) \dagger(P=0.04)$ \\
\hline
\end{tabular}

antioxidant vitamins alone group. Sixty-nine participants discontinued the use of bars because of the development of gestational diabetes: 24 in the placebo group, 23 in the L-arginine plus antioxidant vitamins group, and 22 in the antioxidant vitamins alone group.

\section{Primary end point}

Table 3 shows the findings for the primary end point. The incidence of pre-eclampsia/eclampsia was significantly lower $\left(\chi^{2}=19.41 ; \mathrm{P}<0.001\right)$ in women randomised to L-arginine plus antioxidant vitamins compared with placebo (absolute risk reduction 0.17 , 0.12 to 0.21 ). The number needed to treat (NNT) was $5.73(95 \%$ confidence interval 4.0 to 10.0$)$. Women receiving antioxidant vitamins alone had an observed benefit, but this effect was not statistically significant compared with placebo $\left(\chi^{2}=3.76 ; \mathrm{P}=0.052\right.$; absolute risk reduction $0.07,0.005$ to 0.15 ; NNT $13.06,6$ to 200). The incidence of hypertensive disease was also reduced in the L-arginine plus vitamins group compared with the vitamins alone group $\left(\chi^{2}=8.16\right.$ $\mathrm{P}=0.004)$. Adding L-arginine to antioxidant vitamins compared with vitamins alone resulted in a significant effect on absolute risk reduction $(0.09,0.05$ to 0.14 ; NNT 10.20, 6 to 36).

As enrolment took place over a wide interval from 14 to 32 weeks of gestation, we assessed the relation between gestational age at enrolment and development of pre-eclampsia in women who received L-arginine and antioxidant vitamins compared with placebo. Treatment before 24 weeks reduced the incidence of pre-eclampsia (relative risk $0.37,0.23$ to 0.58 ), whereas treatment after 24 weeks did not $(0.64,0.30$ to 1.37$)$. However, when we estimated the interaction term between treatment effect and time of first treatment, we did not find it to be significant $(\mathrm{B}=0.002 ; \mathrm{P}=0.96)$

\section{Secondary end points}

The overall rate of preterm birth was also reduced in women randomised to L-arginine plus antioxidant vitamins, although this was not because of a reduction in spontaneous preterm births (preterm premature rupture of membranes or preterm labour) (table 3). We found no difference in mean birth weight or in the proportion of small for gestational age infants. Other obstetrical complications, including placental abruption and postpartum haemorrhage, were similar among treatment groups. No maternal deaths occurred. Five neonatal deaths occurred in the study, two in the placebo group and three in the vitamins group. These deaths were associated with extreme prematurity. We found no differences in plasma concentrations of L-arginine between treatment groups at the beginning of the study.

The mean plasma concentration of L-arginine was lower at the first visit in women who later developed pre-eclampsia (20.5, SD 8.3) compared with those who did not develop pre-eclampsia (22.6, SD 8.8) (mean difference 2.01, 95\% confidence interval 0.49 to 3.68 ; $\mathrm{P}<0.01)$. The figures in the web appendix show the concentrations of L-arginine (fig A) and the diastolic and systolic blood pressures (fig B) in the different treatment groups. L-arginine concentrations were highest in the group receiving bars containing L-arginine, and the diastolic and systolic pressures were also significantly lower after initial treatment and negatively correlated with L-arginine plasma concentrations. 


\section{DISCUSSION}

We observed a significant reduction in the incidence of pre-eclampsia/eclampsia in pregnant women who consumed bars containing L-arginine plus antioxidant vitamins. The results of this trial support the proposed hypothesis that supplemental L-arginine can reduce the risk of pre-eclampsia. Consistent with the main study outcome, a secondary finding of the study was that the L-arginine plus antioxidant vitamin supplementation resulted in a significant reduction in the risk of indicated preterm birth compared with placebo.

\section{Methodological considerations and strengths}

Endothelial nitric oxide synthase is constitutively expressed in endothelial cells, and its activity depends on the level of expression of the enzyme, availability of the substrate, and concentrations of at least three different inhibitors that have been associated with preeclampsia. Synthesis of nitric oxide thus depends on the circulating concentration of L-arginine, and adaptive synthesis of nitric oxide in the endothelium is linked to dietary consumption of this amino acid. Our central hypothesis was that impaired vasodilatation in pregnancies complicated by pre-eclampsia could be prevented by supplementation with L-arginine in the diet. The existing literature suggests that L-arginine has direct effects on blood pressure in experimental animal models, normal humans, hypertensive patients, women with pre-eclampsia, and healthy pregnant women. $^{14-22}$

Consistent with recent research, antioxidant vitamins alone did not show a statistically significant reduction in the incidence of pre-eclampsia/eclampsia in our study. Adding L-arginine to antioxidant vitamins resulted in significant protection against the development of pre-eclampsia/eclampsia. Our trial was not powered to detect the small difference we found between the group consuming L-arginine plus antioxidant vitamins and the group consuming bars containing only vitamins. An intriguing result is that supplementing antioxidant vitamins had a statistically significant effect on reducing mild pre-eclampsia. This finding is not consistent with the pooled results of the other clinical trials of antioxidant vitamins, which do not suggest a benefit from treatment. ${ }^{30}$ Recently, the National Institutes of Health's Maternal-Fetal Medicine Units completed a large trial including several institutions in the United States, which reached a similar conclusion. ${ }^{31}$ In addition, detrimental effects of supplemental vitamin $\mathrm{C}$ and vitamin $\mathrm{E}$ during gestation have been reported. ${ }^{303839}$

\section{Limitations of study}

The intervention used in this study must be evaluated in a population of pregnant women at low risk of preeclampsia. This is particularly relevant because we found a high prevalence of recurrence of pre-eclampsia in the studied population. Unfortunately, no information is available from other Mexican centres that could help to identify characteristics associated with this high recurrence rate compared with centres in other countries that have reported lower recurrence of preeclampsia. ${ }^{4041}$

At the time we started this clinical trial, no other commercial presentation for L-arginine was available other than supplemented bars. However, new products containing the amino acid L-arginine in a more palatable presentation are emerging. This makes it feasible to propose a population based study of L-arginine supplementation in larger groups of women with different levels of risk for pre-eclampsia. We did not include a study arm that consumed only L-arginine, as the producer could not supply such bars. In addition, we were aware that L-arginine metabolites may produce deleterious free radicals, ${ }^{42}$ so we considered the inclusion of antioxidant vitamins in the same bars to be beneficial. Unfortunately, our study design could not define the relative contributions of $\mathrm{L}$-arginine and antioxidant vitamins to the beneficial effect of the combination on risk of pre-eclampsia. These ingredients may have had additive effects, or the interaction may have been synergistic. Further studies are needed to clarify these relations. Additionally, our trial was powered to detect a $50 \%$ reduction in pre-eclampsia and was thus not designed to detect smaller differences in risk reduction between L-arginine plus antioxidant vitamins and antioxidant vitamins alone.

We did not find concerning side effects during the supplementation of bars. However, caution is needed in women with peptic ulcer disease, as administration of L-arginine may worsen their symptoms.

The protective effect for pre-eclampsia may be greatest if L-arginine and antioxidant vitamins are supplemented before 24 weeks of gestation. Although our study design did not allow a rigorous test of time of supplementation and outcome, the above noted trend should be considered in the design of future clinical trials to evaluate the efficacy of L-arginine supplementation.

\section{Study in context of previous studies}

Previous attempts to use L-arginine during pregnancy were designed to modify the course of established disease, using the amino acid as a hypotensive agent. ${ }^{43}$ Staff et al showed no effect of L-arginine on clinical course when used in women with pre-eclampsia beyond 28 weeks of gestation. ${ }^{44}$ This is in concert with our findings, in which women who started treatment beyond 24 weeks of gestation did not seem to benefit from treatment. Another clinical trial showed no benefits of arginine supplementation once the disease was established. ${ }^{45}$ However, preliminary evidence indicates that supplementing L-arginine during pregnancy may reduce the risk of pre-eclampsia. Germain et al disclosed some initial findings in women at high risk of pre-eclampsia who received L-arginine from week 10 of gestation. ${ }^{46}$ A small clinical trial of Larginine supplementation in women with chronic hypertension that showed some maternal benefit was published after we submitted our work for publication, supporting the potential benefits of this intervention. ${ }^{47}$ 


\section{WHAT IS ALREADY KNOWN ON THIS TOPIC}

\section{Pre-eclampsia has been shown to be associated with defective vasodilatation}

Defective synthesis of nitric oxide, a key vasodilator, has been documented in pre-eclampsia

Experimental data in animals and humans indicate that supplementation with L-arginine, the substrate for nitric oxide synthase, has a beneficial effect on arterial pressure

\section{WHAT THIS STUDY ADDS}

In a population of women at high risk of pre-eclampsia, dietary supplementation with Larginine and antioxidant vitamins reduced occurrence of the disease

Supplementation with antioxidant vitamins alone did not reduce occurrence of preeclampsia, consistent with previous studies

Further study is needed to determine whether these results can be replicated and to identify whether they are due to L-arginine alone or the combination of L-arginine and antioxidant vitamins
3 Mignini LE, Villar J, Khan KS. Mapping the theories of pre-eclampsia: the need for systematic reviews of mechanisms of the disease. Am J Obstet Gynecol 2006;194:317-21.

4 Sibai B, Dekker G, Kupferminc M. Pre-eclampsia. Lancet 2005;365:785-99.

5 Davidge S. Oxidative stress and altered endothelial cell function in pre-eclampsia. Semin Reprod Endocrinol 1998;16:65-73.

6 Rees DD, Palmer RM, Moncada S. Role of endothelium-derived nitric oxide in the regulation of blood pressure. Proc Natl Acad Sci U S A 1989;86:3375-8.

7 Morris N, Eaton BM. Nitric oxide, the endothelium, pregnancy and pre-eclampsia. Br J Obstet Gynaecol 1996;103:4-15.

8 Visek WJ. Arginine needs, physiological state and usual diets: a reevaluation. J Nutr 1986;116:36-46.

9 Conrad KP, Joffe GM, Kruszyna H, Kruszina R, Rochelle LG, Smith RP, et al. Identification of increased nitric oxide biosynthesis during pregnancy in rats. FASEB J 1993;7:566-71.

10 Savvidou MD, Hingorani AD, Tsikas D, Frolich JC, Vallance P, Nicolaides KH. Endothelial dysfunction and raised plasma concentrations of asymmetric dimetylarginine in pregnant women who subsequently develop pre-eclampsia. Lancet 2003;361:1511-7.

11 Maynard SE, Min JY, Merchan J, Lim KH, Li J, Mondal S, et al. Excess placental soluble fms-like tyrosine kinase 1 (sFlt1) may contribute to endothelial dysfunction, hypertension, and proteinuria in preeclampsia. / Clin Invest 2003;111:649-58.

12 Venkatesha S, Toporsian M, Lam C, Hanai J, Mammoto T, Kim YM, et al. Soluble endoglin contributes to the pathogenesis of preeclampsia. Nature Med 2006;12:642-9.

13 Fraser, R. Pre-eclampsia and diet. In: Strain JJ, Caballero B, Sadler MJ, eds The encyclopedia of human nutrition. Academic Press, 1998:1620-6.

14 Hishikawa K, Nakaki T, Tsuda M, Esumi H, Ohshima H, Suzuki H, et al. Effects of systemic L-arginine administration on hemodynamics and nitric oxide release in man. Jpn Heart J 1992;33:41-8.

15 Campese VM, Amar M, Anjali C, Medhat T, Wurgraft A. Effects of Larginine on systemic and renal haemodynamics in salt-sensitive patients with essential hypertension. J Hum Hypertens 1997;11:527-32.

16 Rosano GMC, Panina G, Cerquetani E, Leonardo F, Pelliccia F, Bonfigli B, et al. L-arginine improves endothelial function in newly diagnosed hypertensives. J Am Coll Cardiol 1998;31:262A.

17 Creager MA, Gallagher SJ, Girerd XJ, Coleman SM, Dzau VJ, Cooke JP. $\mathrm{L}$-arginine improves endothelium-dependent vasodilation in hypercholesterolemic humans. J Clin Invest 1992;90:1248-53.

18 Adams MR, McCredie R, Jessup W, Robinson J, Sullivan D, Celermajer DS. Oral L-arginine improves endothelium-dependent dilatation and reduces monocyte adhesion to endothelial cells in young men with coronary artery disease. Atherosclerosis 1997;129:261-9.

19 Rector TS, Bank AJ, Mullen KA, Tschumperlin LK, Sih R, Pillai K, et al. Randomized, double-blind placebo-controlled study of supplemental oral L-arginine in patients with heart failure. Circulation 1996;93:2135-41.

20 Bode-Boger SM, Boger RH, Galland A, Tsikas D, Frolich JC. L-arginineinduced vasodilatation in healthy humans: pharmacokinetic pharmacodynamic relationship. Br J Clin Pharmacol 1998;46:489-97.

21 Facchinetti F, Neri I, Genazzani AR. L-arginine infusion reduces preterm uterine contractions. I Perinat Med 1996;24:383-5.

22 Neri I, Mazza V, Galassi MC, Volpe A, Facchinetti F. Effects of Larginine on utero-placental circulation in growth-retarded fetuses. Acta Obstet Gynecol Scand 1996;75:208-12.

23 Meher S, Duley L. Nitric oxide for preventing pre-eclampsia and its complications. Cochrane Database Syst Rev 2007;2:CD006490.

24 Hubel CA, McLaughlin MK, Evans RW, Hauth BA, Sims CJ, Roberts IM. Fasting serum triglycerides, free fatty acids, and malondialdehyde are increased in pre-eclampsia, are positively correlated and decrease within 48 hours post partum. Am J Obstet Gynecol 1996;174:975-82.

25 Barden A, Beilin LJ, Ritchie J, Croft KD, Walters BN, Michael CA. Plasma and urinary 8-isoprostane as an indicator of lipid peroxidation in pre-eclampsia and normal pregnancy. Clin Sci 1996;91:711-8

26 Sagol S, Ozkinay E, Ozsener S. Impaired antioxidant activity in women with pre-eclampsia. Int J Obstet Gynecol 1999;64:121-7.

27 Stratta P, Canavese C, Porcu M, Dogliani M, Todros T, Garbo E, et al. Vitamin E supplementation in pre-eclampsia. Gynecol Obstet Invest 1994;37:246-9.

28 Gulmezoglu AM, Hofmeyr GJ, Oosthuizen MM. Antioxidants in the treatment of severe pre-eclampsia: an explanatory randomised controlled trial. Br J Obstet Gynaecol 1997;104:689-96.

29 Chappell L, Seed PT, Briley AL, Kelly F), Lee R, Hunt BJ, et al. Effect of antioxidants on the occurrence of pre-eclampsia in women at increased risk: a randomized trial. Lancet 1999;354:810-6.

1 Ronsmans C, Graham W. Maternal mortality: who, when, where, and why. Lancet 2006;368:1189-200.

2 Meher S, Duley L. Interventions for preventing pre-eclampsia and its consequences: generic protocol. Cochrane Database Syst Rev 2005;2:CD005301. 
30 Rumbold A, Duley L, Crowther CA, Haslam RR. Antioxidants for preventing pre-eclampsia. Cochrane Database Syst Rev 2008;1:CD004227.

31 Roberts JM, Myatt L, Spong CY, Thom EA, Hauth JC, Leveno KJ, et al. Vitamins $C$ and $E$ to prevent complications of pregnancy-associated hypertension. N Engl J Med 2010;362:1282-91.

32 Papapetropoulos A, Garcia-Cardeña G, Madri JA, Sessa WC. Nitric oxide production contributes to the angiogenic properties of vascula endothelial growth factor in human endothelial cells. J Clin Invest 1997;100:3131-9.

33 Maxwell AJ, Anderson BE, Cooke JP. Nutritional therapy for peripheral arterial disease: a double-blind, placebo-controlled, randomized trial of HeartBar. Vasc Med 2000;5:11-9.

34 Pickering TG, Hall JE, Appel LJ, Falkner BE, Graves J, Hill MN, et al. Recommendations for blood pressure measurement in humans and experimental animals. Part 1: blood pressure measurement in humans: a statement for professionals and public education of the American Heart Association Council on High Blood Pressure Research. Hypertension 2005;45:142-61.

35 Orsonneau J, Douet P, Massoubre C, Lustenberger P, Bernard S. An improved pirogallol re-molybdate method for determining total urine protein. Clin Chem 1989;35:2233-6.

36 Lundsjo A, Hagelberg S, Palmer K, Lindblad BS. Amino acid profiles by HPLC after filter paper sampling: "appropriate technology" for monitoring of nutritional status. Clin Chim Acta 1990;191:201-10.

37 Levine M, Walter S, Lee H, Haines T, Holbrook A, Pharm D, et al. User's guides to the medical literature. IV: how to use an article about harm. JAMA 1994;271:1615-9.

38 Podmore ID, Griffiths HR, Herbert KE, Mistry N, Mistry P, Lunec J. Vitamin C exhibits pro-oxidant properties. Nature 1998;392:559.

39 Banerjee S, Chambers A, Campbell S. Is vitamin E a safe prophylaxis for pre-eclampsia? Am J Obstet Gynecol 2006;194:1228-33.
40 Hnat MD, Sibai BM, Caritis S, Hauht J, Lindheimer MD, MacPherson C, et al. Perinatal outcome in women with recurrent pre-eclampsia compared with women who develop pre-eclampsia as nulliparas Am J Obstet Gynecol 2002;186,422-6.

41 Hjartardottir S, Leifsson B, Geirsson R, Steinhorsdottir V. Recurrence of hypertensive disorder in second pregnancy. Am J Obstet Gynecol 2006;194:916-20.

42 Rubbo H, Radi R, Trujillo M, Telleri R, Kalyanaraman B, Barnes S, et al. Nitric oxide regulation of superoxide and peroxynitrite-dependent lipid peroxidation: formation of novel nitrogen-containing oxidized lipid derivatives. J Biol Chem 1994;269:26066-75.

43 Facchinetti F, Longo M, Piccinni F, Neri I, Volpe A. L-arginine infusion reduces blood pressure in pre-eclamptic women through nitric oxide release. J Soc Gynecol Investig 1999;4:202-7.

44 Staff AC, Berge L, Haugen G, Lorenzen B, Mikkelsen B, Henriksen T. Dietary supplementation with L-arginine or placebo in women with pre-eclampsia. Acta Obstet Gynecol Scand 2004;83:103-7.

45 Rytlewski K, Olszanecki R, Korbut R, Zdebski Z. Effects of prolonged oral supplementation with $\mathrm{L}$-arginine on blood pressure and nitric oxide synthesis in pre-eclampsia. Eur J Clin Invest 2005;35:32-7.

46 Germain AM, Valdez G, Romanik MC, Reyes S. Letter to the editor: evidence supporting a beneficial role for long term L-arginine supplementation in high-risk pregnancies. Hypertension 2004;44:e1.

47 Neri I, Monari F, Sgarbi L, Berardi A, Masellis G, Facchinetti F. Larginine supplementation in women with chronic hypertension: impact on blood pressure and maternal and neonatal complications. J Matern Fetal Neonatal Med 2010;23:1456-60.

Accepted: 28 March 2011 